\title{
Affirming the American Dream via the Sports /Film Star
}

\author{
By Seán Crosson
}

Fall 2014 Issue of KINEMA

\section{FROM BABE RUTH TO MICHAEL JORDAN: AFFIRMING THE AMERICAN DREAM VIA THE SPORTS /FILM STAR}

\author{
Its drama, its personalities and its worldwide appeal \\ means sport is the new Hollywood \\ - Bell and Campbell (1999: 22)
}

Celebrity is a crucial aspect of contemporary culture and one to which both sport and film make a substantial contribution. In film, the 'star image' that has developed around individual actors is a multifaceted, complicated and sometimes contradictory phenomenon composed of the roles they have played, their carefully orchestrated public appearances and the depictions of the creation of a star's image, as well as the actual individual around whom this image has evolved. However, arguably what is most significant about individual stars is the manner through which they express facets of living in today's society, including the nature of labour in the capitalist world (Dyer, 1986: 7-8). Stars are particularly important in defining what it means to be a person or individual. Indeed, the notion of individuality, so central to contemporary capitalist culture and in particular the American Dream ideology, is crucial to the star phenomenon. As David L. Andrews and Steven J. Jackson contend regarding contemporary celebrities, drawing on the work of P. David Marshall (1997),

The contemporary celebrity is an embodiment of the twinned discourses of late modernity: neoliberal democracy and consumer capitalism. Indeed, Western liberal democracy represents a political system preoccupied with 'the personal, the intimate, and the individual'; incorporates an equally solipsistic regime of economic (re)production (consumer capitalism); both of which are nurtured by the supreme technology of hyper-individualization (commercial television) (Andrews and Jackson, 2001: 1).

However, throughout history from works of the enlightenment such as David Hume's An Enquiry Concerning Human Understanding (1748), to Marx's writings, and developments in psychoanalysis and linguistics, the notion of the independent individual has been repeatedly questioned and subject to doubt. Nonetheless, individualism has continued to be a central, indeed defining, tenet of capitalism which prides itself on the 'freedom' it provides to the individual entrepreneur or consumer. In this context, stars have a crucial role to play, 'shoring up the notion of the individual but also at times registering the doubts and anxieties attendant on it' (Dyer, 1986: 9-10). Indeed, a trait that athletic stars share with film stars is the perception among the general public that they are in some respect unique. Crucially, stars in the public eye throughout their careers affirm the coherence of the individual. For Dyer,

This coherent continuousness within becomes what the star 'really' is. Much of the construction of the star encourages us to think this. Key moments in films are close-ups, separated out from the action and interaction of a scene, and not seen by other characters but only by us, thus disclosing for us the star's face, the intimate, transparent window to the soul (Dyer, 1986: 11).

In the contemporary media presentation of sporting stars, a similar process can be identified. Since the advent of television, athletes are now depicted with an intimacy and detail very similar to that found in film. Athletes' every move and expression are captured for audiences, a development exemplified in the 'player cam' facility now available to viewers of sporting events on some satellite channels allowing them to follow every action of individual players during games. In these televisual renderings, athletes exemplify the prominence of individual performance in contemporary capitalist culture, a feature evident throughout the history of cinematic depictions of sporting figures.

\section{Why Sport Celebrities?}

In their introduction to their collection Sport Stars (2001), Andrews and Jackson have identified three 
principle reasons for the appeal of sporting celebrities. Firstly, the reduction of sport celebrity to individual qualities such as 'innate talent, dedication, and good fortune', position the sport star as 'a deserved benefactor of his or her devotion to succeed within the popular imaginary' (Andrews and Jackson, 2001: 8). This conception of sport as essentially meritocratic continues to have resonance today and is one of its most attractive aspects for those who wish to exploit sport, and leading athletes, for commercial gain (Crosson, 2013: 66-102). As Richard Giulianotti observes,

The cultural illusion is fostered that, one day, the 'ordinary but special' individual consumer may realize his or her unique qualities, and join the ever-changing pantheon of celebrities. Sport has a particular potent role to play within this ideological formation (Giulianotti, 1999: 118-19).

Secondly, sport is a 'uniquely valued cultural practice' that can engage national and sometimes global sensibilities, providing a superb vehicle to communicate particular messages (Andrews and Jackson, 2001: 8). Finally, the athletic star differs from the film star in that while Dyer views a star's overall image as separate from a character they may be associated with in particular films, athletes are not performing in fictional roles within their profession. Though sometimes accused of 'acting', most often by feigning injury, professional athletes are ultimately engaged in sport for their livelihood, rather than performing as a sportsperson (as in the case of a film actor). James Monaco has described celebrities as the 'passive objects of the media' (Monaco, 1978: 6), but the sports star is different to the celebrity 'well-known for being well-known' in that, at least initially, their fame arose from their actions in their professional life as athletes.

While athletes may receive attention, fame and celebrity for their actions off-field, it still usually requires some degree of success, or at least distinction, as professional sports people for the media's initial interest to arise. Much of the international fame and celebrity that association football players such as George Best and more recently David Beckham have enjoyed may involve aspects of their non-playing lives, and relationships, but it is their initial success as attractive, stylish and talented footballers that caught the media's attention. However, this very aspect of sports stars adds an additional level of importance to their roles as celebrities. As Andrews and Jackson contend, unlike music or film stars who are associated with fictive identities, in sport

there is a perception that spectators/viewers are confronted with real individuals participating in unpredictable contests. Hence, the seeming visceral, dramatic immediacy of the sport practice provides the sport celebrity with an important veneer of authenticity, that sets him or her apart from celebrities drawn from other, more explicitly manufactured, cultural realms (Andrews and Jackson, 2001: 8)

These connotations which sport evoke have also encouraged actors to attempt to enhance their star personas through association with sport. Hollywood in the early twentieth century has been described as the 'most sports-minded American community'(Manchel, 1980: 16), with film stars frequently linked with sport, from their daily regimes of swimming pools and gymnasiums to their ownership of baseball teams, as in the case of former semi-pro baseball player Joe E. Brown. Brown had a clause in his contract when he signed for Warner Bros. in 1929 ensuring the studio's support for his baseball team, the Joe E. Brown All-Stars (Fuller, 1991: 56), while most of his films in the 1930s had a sporting subject, including boxing (Hold Everything, 1930) and When's Your Birthday?1937), Wrestling, Sit Tight (1931), Swimming, You said a Mouthful (1932), Football, Maybe it's Love (1930), Athletics, (Local Boy Makes Good (1931), cycling, 6 Day Bike Rider (1934), polo (Polo Joe (1936), and three baseball pictures, Fireman, Save My Child (1932), Elmer the Great (1933) and Alibi Ike (1935). Indeed, Richard Dyer has contended that for many male films stars, including Clarke Gable, Humphrey Bogart, Paul Newman and Steve McQueen,

sporting activity is a major - perhaps the major - element in their image: they are defined above all else as people for whom having uncomplicated fun is paramount, and this is implicitly carried over into their reported attitude to their work. But equally work isn't important, it's just something you do so as to have the wherewithal to play polo, sail yachts, race cars (Dyer, 1986: 7).

Many contemporary Hollywood male stars continue to have important associations with sport including Kevin Costner (part owner of Minor-League baseball team Lake County Fielders and star of five baseball- 
themed films to date) and Sylvester Stallone (best known as the star of the Rocky franchise), while its difficult to find a major male Hollywood star who does not count at least one prominent sports film (or in the case of Will Ferrell four) among their films, including Robert De Niro (Raging Bull, 1981), Robert Redford (The Natural, 1984), Gene Hackman (Hoosiers, 1986), Tom Selleck (Mr. Baseball, 1992), Adam Sandler (Happy Gilmore, 1996; The Waterboy, 1998; The Longest Yard, 2005), and Brad Pitt (Moneyball,2011).

\section{The Origins of Sport and Film Celebrities}

The sport celebrity owes its origins to the establishment by William Randolf Heart in 1895 of the first newspaper sports section within The New York Journal (Andrews and Jackson, 2001: 6). Such sections began to feature increasingly in newspapers across the US and internationally and provided an important forum for the emergence of sports stars. The arrival of cinema would also contribute to this process as the huge appeal of boxing legends such as 'Gentleman' Jim Corbett had a crucial role in the popularising of the new medium of film through his appearance in some of the earliest works produced, particularly the Corbett-Fitzsimmons Fight (1897), regarded as the first feature length film to be produced. Indeed, Corbett has been described as the first 'movie star' signing a film contract after his retirement from professional boxing and appearing in a series of shorts as himself before starring in feature films including The Burglar and the Lady (1914), The Other Girl (1916) and The Prince from Avenue A (1920) (Edgington, Erskine and Welsh, 2010: viii).

The emergence of film stars is particularly associated with the rise of narrative fiction film at the beginning of the twentieth century. As Rick Altman has argued, the development of stars, and of film genres, was due to a concern to 'restore the sensation of presence' to the film-going experience as audiences became increasingly removed physically, and in terms of subject matter, from the topics of individual film. In the first actuality films produced, viewers were likely to see local people or places they knew well as filmmakers attempted to instil a sense of presence to the cinema. However, with the arrival of narrative cinema this was no longer the case. However the development of the star system provided a means of restoring this presence to the cinema as the cinema viewer saw

characters who had little by little become the regular companions of his visits to the cinema. Soon he would be calling actors and actresses by name and recognizing them more easily than his business acquaintances (Altman, 1999: 187).

In this context, well-known athletes played an important role and in the silent period, athletes featured with increasing regularity in film. Reflecting its popularity more generally in American culture in the period, and indeed its much mythologised position as 'America's Game', baseball players in particular were found repeatedly in film roles in the 1910s, including the controversial first baseman Hal Chase who featured in Hal Chase's Home Run (1911), and Philadelphia Athletics third baseman Frank 'Home Run' Baker who starred in The Short-Stop's Double (1913) and Home Run Baker's Double (1914). Other players featured in early films were the New York Giants pitcher Christy Mathewson and then Giants' manager John McGraw in Breaking into the Big League (1913), the Chicago Cubs star first baseman Frank 'The Peerless Leader' Chance in Baseball's Peerless Leader (1913), and legendary Detroit Tigers outfielder Ty Cobb in Somewhere in Georgia (1916). Film provided opportunities for such players to supplement their modest incomes in this period while also allowing them to increase their profile off the ball park and in some instances find alternative careers in film (Noverr, 1993: 172-173). These films also gave baseball fans, many of whom would not have been in a position to go to Major League games, an opportunity to see their favourite players playing the game at a time when pictures and images of baseball players were limited.

Successful athletes also attracted the attention of Hollywood studios, particularly from the third decade of the twentieth century. The 'Roaring Twenties' was a period in which the figure of the national sporting hero became established in the US popular consciousness with sporting heroes like Babe Ruth, Knute Rockne and Jack Dempsey coming to prominence. Cinema also played a significant role in the development of such sporting celebrities and others such as American footballer Harold 'Red' Grange, particularly with the emergence of newsreels, including the sports newsreel introduced from 1911, which helped contribute to the cultivation of star personas surrounding these athletes (Trimble, 1996: 47). These newsreels offered glimpses into the private lives of players, several of whom also featured in narrative films in this period.

Wiley Lee Umphlett has identified how 'The sports flavour' of many of the most successful college-life films 
of the 1920s was contributed to by the inclusion of popular athletes of the period in either lead or supporting roles. These included American athlete and double Olympic champion Charlie Paddock who appeared as himself in The Campus Flirt (1926), the University of Alabama All-American football player Johnny Mack Brown who featured as a basketball coach in The Fair Co-ed (1927) and 'Red' Grange who plays against type as a college student who refuses to play football in One Minute to Play (1926) (Umphlett, 1984: 29). Indeed, successful athletes were frequently found in film roles in this period including American footballer Jim Pierce, basketball player Denny Miller, Olympic shot putter Bruce Bennet, legendary tennis player Bill Tilden, and professional boxer Max Baer who featured in the lead role as boxer Steve Morgan in The Prizefighter and the Lady (1933) (a film that also featured former world champions, Jess Willard, Jim Jeffries and Jack Dempsey), a year before Baer actually won the world heavyweight title. Such recognisable sporting figures in some cases added considerably to the appeal of the films in which they appeared, particularly 'assigning low-keyed films a magnetic box office attraction they would never otherwise have had' (Umphlett, 1984: 29).

However, opportunities for female athletes to make this transition were limited in the early twentieth century. When they did, they performed in roles evincing traditional feminine qualities, such as grace, balance, and beauty, and in sports that had little or no physical contact between competitors. Examples include Norwegian ice-skater Sonja Henie who specialised in musicals set on ice and managed to make the transition from sport to film with some success, and Esther Williams, who began as a successful competitive swimmer before being signed by MGM in the early 1940s. Henie won gold at just 16 at the 1928 Winter Olympics at St. Moritz, a feat she repeated at the 1932 (Lake Placid) and 1936 (Garmisch) Games. Following her 1936 victory she was signed by Darryl F. Zanuck of Twentieth Century Fox for a fee of $\$ 75,000$ to star in One in a Million (1936) and she starred in seven further films for the studio, becoming one of its greatest attractions (Hirschhorn, 1981: 129). Williams enjoyed great commercial success in the late 40s and the early 1950s in a string of films, some of which had sporting themes, in particular Take me out to the Ballgame (1949) and Million Dollar Mermaid (1952), a biographical musical concerning legendary Australian swimmer and film star Annette Kellerman. Kellerman herself had also made the transition from successful swimmer to actress with some success during the silent era, starring in a series of aquatic themed films including The Mermaid (1911), Queen of the Sea (1918) and Venus of the South Seas (1924).

Such examples as Kellerman, Henie and Williams were, however, exceptions as sports films were primarily areas for the affirmation of masculine values, a theme also apparent in the films in which such athletes were depicted (Crosson, 2013: 104-124). Like women, successful African American athletes in the early twentieth century also found few opportunities in films, reflecting the limited roles more generally given to African Americans in early cinema, and the resistance to strong African American figures, such as boxer Jack Johnson, that persisted well into the twentieth century. The sport film for much of the first half of the twentieth century was primarily a White male preserve.

Ronald Bergan has partly attributed the adulation that both successful athletes and film stars receive to 'the fact that they have succeeded within a circumscribed territory where issues are clearer and more easily grasped than in the confusion of world politics and everyday life' (1982: 5). However, stars play an important ideological role, identified by Orrin E. Klapp, whereby they 'reinforce a person in social roles - encourage him to play those which are highly valued - and ... maintain the image of the group' (Klapp, 1969: 219). Indeed, stars provide a means of embodying the dominant ideology while resolving inherent contradictions, including those surrounding the American Dream of opportunity, upward social mobility and material success. This is particularly so with sport stars, where their ideological role has been assisted by their apparent apolitical status. Within the United States, they have affirmed that country's democratic ideals and the American Dream ideology, epitomised in such sporting jargon as 'fair play' and 'good sportsmanship', promoted as part of the vigorous competition which elite sport requires. As noted by Rader, athletes in films provide 'compensatory' heroes, particularly in challenging times such as the Great Depression, that help to alleviate concerns among the public regarding 'the passing of the traditional dream of success, the erosion of Victorian values and feelings of powerlessness' (Rader, 1990: 11).

\section{Babe Ruth}

A relevant figure in this respect was the celebrated baseball player Babe Ruth (fig. 1) who was particularly successful in building on his on-field achievements to earn very lucrative sponsorship and appearance deals. Indeed, so successful was Ruth in this respect, and so influential was the print, newspaper, and cinematic 
coverage of him, that the term 'Ruthian' is now used to describe a superb performance or individual achievement (Andrews and Jackson, 2001: 6). In his image of excessive consumption combined with prodigious ability, Ruth provided an ideal figure to promote American consumer culture. As Rader contends, he had a unique ability to

project multiple images of brute power, the natural uninhibited man and the fulfilment of the American success dream. Ruth was living proof that the lone individual could still rise from mean, vulgar beginnings to fame and fortune, to a position of public recognition equalled by few men in American history (Rader, 2008: 130)

Indeed, Ruth was himself fond of contributing to this legend, remarking in his ghost written autobiography that 'The greatest thing about this country is the wonderful fact that it doesn't matter which side of the tracks you were born on, or whether you're homeless or homely or friendless. The chance is still there. I know' (quoted in Rader, 2008: 130).

Ruth, one of the most prolific hitters in Major League baseball history, starred in a series of films during his time playing in the Majors, particularly after his move from the Boston Red Sox to the New York Yankees in 1919. In these films, Ruth always played himself or characters loosely based on his star persona, including in Headin' Home (1920), Babe Comes Home (1927) and the Harold Lloyd box-office hit Speedy (1928) (fig. 1). As with other films featuring sporting celebrities, these works exploited Babe's iconic status for their appeal while contributing to his 'ruthian' image and affirming the American Dream of success in the process. Babe's first feature film Headin' Home (1920) was an early representative example of the mass-marketing of baseball. It was released as a showcase film and screened in the largest and most prestigious venues of the day, including the 10,000 seater Madison Square Garden (Trimble, 1996: 51-52). The Garden screening was a huge media event, that included, according to contemporary reports, 'a circus-like atmosphere' with 'numerous items being sold during the show, everything from Babe Ruth autographs and records to sheet music for a song called "Oh, You Babe Ruth" which Tim Bryan and his band played over and over again' (Trimble, 1996, p. 52).

Ruth played himself in Headin' Home in this entirely fictionalised account of his life in which he rises from humble small town beginnings in the 'little egg and hamlet in the sticks' Haverlock where he is mocked for his clumsiness, to star player with the New York Yankees. This theme of the seeming simpleton with limited apparent ability overcoming the odds and turning out to be a gifted athlete would be a recurring trope of many subsequent productions, including more recent films such as Forrest Gump (1994) and The Waterboy (1998). It provides a powerful affirmation again of the American Dream ideology suggesting that even for those of seeming limited intelligence the dream remains a possibility, particularly if they show a talent for sport. While Headin' Home is a much sanitised version of Babe's life, depicting him as coming from a loving home - rather than the more difficult childhood he actually experienced in a Baltimore reformatory - the trajectory of rags-to-riches is nonetheless to the fore while the film emphasises Babe's moral character in his supportive relationship with his widowed mother and foster sister 'pigtails'. These themes were particularly important for audiences in the 1920s. For Patrick Trimble

Headin' Home and its surrounding publicity perpetuated the cultural image of Babe Ruth as an American success story. His individualism and hedonistic sense of self-fulfilment were an affirmation of many of the personal values that were most admired in a cultural celebrity during the 1920's. The public perceived that his humble beginnings created strong moral fiber, while individual ability and courage provided personal growth and financial well-being (Trimble, 1996: $53)$.

Following World War II, sport celebrity was contributed to greatly by the arrival of television. Television brought an intimacy to depictions of sports celebrities which when combined with the advent of live television coverage of sporting events increased substantially the profile and impact of athletes on the general public. However, though television became quickly the most important medium for sport, its depictions were, and continue to be, considerably influenced by the cinema. Whannel's description of television sport as 'presented largely in terms of stars and narratives: the media narrativises the events of sport, transforming them into stories with stars and characters, heroes and villains' (Whannel, 1998: 23) indicates the significant influence of the cinema on contemporary televisual sporting representations. Furthermore, television has also attempted 
to appropriate some of the aesthetic values of film in its presentations, evident for example in the addition of sound effects to televisual coverage of live sporting events and also in the frequent use of music, much as is found on a film's soundtrack, to add to the drama of the sports represented.

Television has contributed to the extraordinary growth of sporting celebrity and its increasing complexity, apparent in a broad range of areas of contemporary life. Through global sports and media groups such as International Management Group (IMG), SFX and Octagon, the creation of sporting celebrities has become a sophisticated and highly profitable enterprise while the areas in which sport celebrities now function as significant economic and cultural figures has extended well beyond the ring or field of play. Increasingly sports celebrities are found in a broad range of popular entertainment from TV shows, to talk shows, musical recordings, websites and video games. As Andrews and Jackson contend, drawing on a concept coined by Andrew Wernick (1991), 'within today's multi-layered "promotional culture", the sport celebrity is effectively a multi-textual and multi-platform promotional entity' (Andrews and Jackson, 2001: 7).

\section{Michael Jordan}

A leading example of this development of sporting celebrity is legendary basketball player Michael Jordan. Jordan was one of the most successful athletes ever in the US, winning 6 National Basketball Association (NBA) titles with the Chicago Bulls. However, he was also one of the most important and commercially lucrative figures in recent American history associated with an array of products, from Nike athletic shoes, to Ball Park Franks Hotdogs and Bijan cologne (to name but a few), many of which benefited hugely from his association. Unlike many other American athletic stars, Jordan's success has translated into international stardom such that in a 1992 Chinese survey, 'schoolchildren ranked him with Zhou Enlai as the two greatest figures in twentieth-century history' (LaFeber, 1999: 27). However, his apparent ability to seemingly transcend race, gender and class lines in the United States disguises the central role he has played in obscuring such real divisions and structural inequalities within American society, a role evident in his 1996 film Space Jam.

Jordan was but one of a series of basketball stars to feature in films since the 1980s, including Kareem Abdul-Jabbar (Airplane, 1980), Dennis Rodman (Double Team, 1997), Shaquille O'Neal (Kazaam, 1996) and Ray Allen (Harvard Man, 2001). However, Space Jam attracted a considerably larger box office than any of these other films listed, and remains to date the most commercially successful basketball film ever released taking over $\$ 90$ million in the US alone and a total worldwide gross of $\$ 230,418,342 .{ }^{(1)}$ Significantly, unlike many other successful American sports films, the majority of the film's box office came from overseas sales indicating Jordan's huge appeal internationally. Jordan himself benefited substantially from the film, not just the considerable fee paid for his appearance, but also from the deal he did with the film's producers for 10 per cent of merchandising receipts from the film (Tudor, 1997: 31).

As a player, Jordan was a figure around whom a myriad of meanings and resonances circulated, many of which are central to the American Dream ideology. Individualism is a crucial aspect of this ideology, exemplified in the independent self-made man who overcomes marginalisation or various socio-economic challenges to achieve success. As Deborah Tudor has argued, 'Representations of Black stars created and maintained the concept of the individual athlete-hero-star' (1997: 32), evident in Jordan's case in the manner through which he was frequently matched up with leading players from opposing teams in advertisement promos for upcoming games. The effect of such representations and its exaggeration through advertising is to effectively transform what is a team game into a one-on-one contest. Indeed, the very style of play associated with Jordan is one in which individualism is prioritised. Halberstam (2009) and Ashe (1993) have both identified a Black playground style of basketball, a style which was evident in the play of Jordan and other leading African American players that focuses more on complicated individual moves than coordinated team endeavour. Though based in inner city basketball, this style has increasingly become part of the NBA with the domination of this sport by African American players and the foregrounding of spectacle in the sport's televisual presentation. This focus on individual stars was also a crucial part of broadcasters attempts to increase the at first disappointing viewership for basketball games on television (Tudor, 1997: 32-35).

The theme of individualism was evident from early in Jordan's career and was a defining aspect of his promotion by early sponsors, Nike and Coke. Few other athletes attracted the same level of sponsorship and have been associated with as many consumer products as Jordan. He was one of the supreme examples of 
the capitalist consumerist phenomenon described by Rick Altman:

Consumers within a capitalist society do not just accept what is offered. Their choice of products is a source of pleasure, pride and even identity. This is why genres, sports and stars loom so large in the twentieth-century firmament. Whatever power they have comes from their users, who need the identity - albeit imagined - provided by these phenomena (1999: 193).

One of the first Nike advertisements for the Air Jordan range, titled 'Jordan Flight', featured Jordan scoring a slam dunk and concluded with the question 'who said man was not meant to fly'. In a subsequent Coke advert, Jordan is depicted leaping ET like across a silhouette of the moon to grab a bottle of coke. As McDonald and Andrews note, in 'both cases the metaphor of flight is used to link Jordan's sign value with the enduring American ideologies of competitive individualism' (2001: 22). Indeed, for these writers, Nike

has built Jordan's image in accordance with the dominant structure of the feelings that are continuously effectively rearticulated in relationship to American consumer culture, including those of the American Dream, rugged individualism and the value of personal perseverance (2001: $23)$.

It is these values that are prioritised from the opening pre-credit sequence of Space Jam. The film opens with a crane shot which swoops down, capturing the night sky, a shooting star and the full moon before revealing a young boy playing basketball in the front yard of his house. As the camera focuses in on the boy, the sounds of R Kelly's 'I believe I can fly' are heard on the soundtrack. In this one camera movement and complementary music, the film connects with the popular representation of Jordan, including the Nike and Coke advertisements mentioned above. A title reveals its summer 1973 and as the young boy continues to score baskets, a light comes on in the house and an older figure looks out admiringly at the child. When he calls him 'Michael', we are confirmed, if there was any doubt, in our presumption that this was a young Michael Jordan practicing the game at which he would excel in subsequent years. 'What are doing out here son, it's after midnight' Jordan's father asks. In this remark, the immense dedication, hard work, and perseverance required to achieve sporting success are already evident as a feature of the young Jordan. In the early presentation of these values, and the knowledge among audiences of Jordan's later success, this moment affirms a central tenet of the American Dream ideology, that hard work will bring success.

This theme of perseverance was also evident in advertisements featuring Jordan, including one particular Nike advertisement which emphasised the importance of hard-work, and indeed failure, to success, evident in Jordan's voice over quoted below.

I've missed more than 9,000 shots in my career. I've lost almost 300 games. 26 times I've been trusted to take the game winning shot and missed. I've failed over and over and over again in my life and that is why I succeed (cited in McDonald and Andrews, 2001: 23).

This focus on hard work, while balancing the value of natural talent for sporting success, also has sociological implications. By foregrounding the importance of hard work, such representations as these featuring Jordan assure those who lack such talents - the vast majority of people - that they too can succeed. Sport has the unique ability to on the one hand elevate a small number of exceptionally talented individuals while suggesting that the success they enjoy is available to all through hard work and perseverance. However, this message disguises and obscures the obstacles those wishing to succeed in professional sport must face (Tudor, 1997: xxi). Furthermore, much as sport is used as a recurring metaphor in society for life itself, ${ }^{(2)}$ such a trajectory also suppresses the restrictions and structural obstacles to success and the achievement of the American dream for many.

Indeed, sport is clearly linked to progress and success in the opening scene of Space Jam, as Michael asks his father 'Do you think if I get good enough I can go to college'. That this sentence can be included without any sense of irony is a remarkable revelation of the role of sport in the United States, and particularly among the African American community. Sporting ability, it is suggested, rather than intelligence and academic acumen, determine access to third level education. The response of Jordan's father suggests sport as not just a way of accessing education, however, but beyond this a means of realising the American Dream itself: 'If you get good enough you can do anything you want to Michael'. The reality, however, is that very few African Americans will actually realise their ambitions through sport. Indeed, this focus on sport has in many 
cases contributed to the failure of members of this community to achieve recognition and success in other professions in which they are more likely to succeed. ${ }^{(3)}$ However, given the influence Jordan had within the African American community as one of that community's most successful athletes, this interchange between father and son and this scene as a whole is a powerful affirmation of the myth that the path to achieving the American Dream for African Americans is via sport.

The young Jordan subsequently lists off his ambitions in Space Jam - all of which would subsequently be achieved - to his father, including playing on the North Carolina University championship team and eventually in the NBA. However, this scene does not just foreground basketball, but also baseball, a sport that the young Jordan also expresses a wish to play in, as his father had done: 'Baseball, now that's a sport' his father remarks. Given the mythological associations of baseball as the American sport and its connections with the American Dream ideology (Robson, 2010; Fuller, 1991), this adds further to the associations in this scene with this dream overall.

And to close, the scene connects again with the theme of flight, so pervasive throughout Jordan's career, as his father remarks: 'and when you're finished with that I suppose you're gonna fly', providing the motivation for a segue to the adult Jordan in full flight on the basketball court. In this opening credit sequence, it is again Jordan's individual brilliance that is foregrounded, with repeated shots of extraordinary slam dunks by the player - which earned him the nicknames 'Air Jordan' and 'His Airness' - followed by images and footage depicting his progression from childhood to adulthood. This focus on Jordan's individual brilliance recurs throughout the film including one sequence about half way through when he demonstrates to the Looney Tunes characters with whom he plays basketball that he has lost none of his ability as a player despite retiring. Complemented by the strains of 'Fly Like an Eagle' sung by Seal on the soundtrack, Jordan enters the scene captured by a low-angle backlit shot that tilts upward to emphasise his height and impressive physique. The scene subsequently features recurring shots of Jordan scoring one impressive slam dunk after another, many captured by high-angle shots that contribute to the sense of a player in flight.

Jordan's sponsor Nike is itself associated with one of the best known and most successful advertising slogans in history, the individualistic motto 'just do it'. While using the remarkable athletic achievements of Jordan to promote their brand, Nike have, however, also exploited their association with the former player to overcome negative publicity surrounding poor labour conditions of those workers in the developing world who produce Nike goods ('Nike workers ...', 2011). Similarly, though Jordan has been elevated as a supreme example of African American success, his depiction in the media has drawn on regressive racial discourses, in particular, as observed by McDonald and Andrews, the

discourse of extraordinary athleticism [which] relies upon common sense assumptions of an innate Black physicality, a racist characterization once used to justify the institution of slavery and Social Darwinist constructions of White supremacy (2001: 24).

Jordan's position as an exemplar of African America relates to important political and cultural developments during the 1980s and 1990s and his usefulness to the emergence of a new right conservative regime, led initially by Ronald Reagan. In this context, Jordan was promoted through advertising and in association with government-lead campaigns such as 'Just say no to Drugs', as a 'hard body' capable of restraint and self discipline, in contrast to the urban 'soft bodied depictions of Black masculinity as deviant' (McDonald and Andrews, 2001: 27) Such depictions, while appearing to elevate Jordan, did so while simultaneously demonizing and criticising the millions of African Americans who lived in considerable poverty and appeared to lack, following from the conservative logic of individualism that underpinned Reaganism, the requisite resolution to achieve the American Dream.

Jordan's depiction also connected with popular cinematic depictions in the 1980s and 1990s that also affirmed this individualist ideology. Films such as Rambo: First Blood Part II (1985) connected with the political focus on individualism in the period of their release and sometimes even provided inspiration for political leaders. This was evident in the remarks of Ronald Reagan after the release of 39 American hostages from Beirut in June 1985, when the President remarked 'After seeing Rambo last night, I know what to do next time this happens'. While seeking tax reform some months later, Reagan returned to Rambo again remarking, 'Let me tell you, in the spirit of Rambo, we're going to win this thing' (Lane, 2008). 
The focus on Jordan's masculinity and physicality were, however, carefully balanced in the popular media by his depiction as a 'gentle' family man off the court, a depiction crucial to his elevation to a mass cultural icon without evoking disproportionate White cultural disquiet. This diffusion of the threat that Jordan's African American masculinity and sexuality may have presented is evident in the series of commercials Jordan completed where he was paired with various Looney Tunes characters, including Bugs Bunny, Porky Pig and Elmer Fudd. Jordan's association with Looney Tunes characters is also a central feature of Space Jam (fig. 2), where he is teamed up with these Looney Tunes characters against an evil team from outer space, 'The Mon-Stars'. In the film, Jordan is pulled down a hole on a golf course in '3D land' by Yosemite Sam and brought into Looney Tune cartoon space where his physical body follows the laws associated with characters normally found in this sphere. Indeed, Jordan is literally reduced to a basketball in one scene by members of the Mon-stars, and again like other cartoon characters unhurt by the experience. He eventually leads his Looney Tunes team to victory with an impressive final second dunk where he flies from the halfway line, while been dragged back by several of the Mon-Stars, his arm eventually stretching, cartoon like, an extraordinary distance to score the basket. As Tudor contends, this association is part of a general pattern in the representation of Jordan whereby the 'text of Michael Jordan's image presents a Black man as if he were not a man, but a child' (1997: 43).

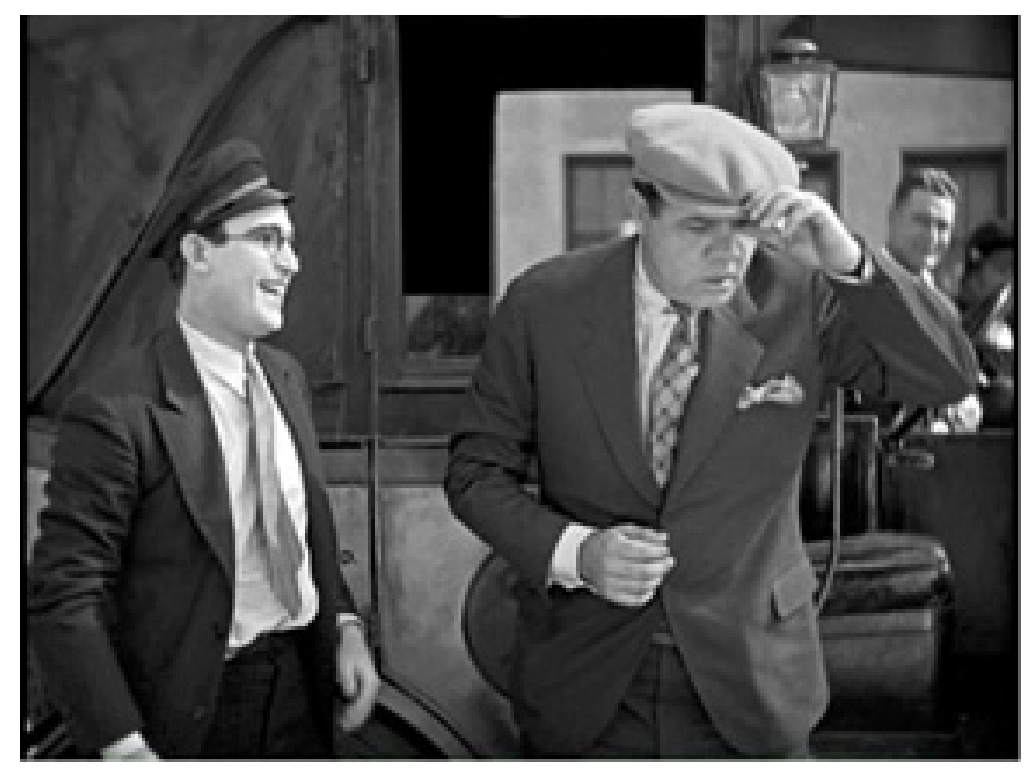

Figure 1: Figure 1: Babe Ruth as himself (on the right) in the Harold Lloyd film Speedy (Paramount Pictures, 1928).

While many of the advertisements associated with Jordan featured children - including adverts for Coke and Chevrolet - others have featured Jordan's parents or his wife and Jordan has foregrounded his family in interviews, including in his retirement speech:

Unfortunately, my mother, my family, brothers and sisters, could not be here. But as you see me, you see them. My father, my mother and certainly my brothers and sisters. They are here, through me, and they, along with myself, say thank you for taking me in and showing me the respect and gratitude you have shown me over the years I have been here (quoted in McDonald and Andrews, 2001: 29).

Jordan's focus on his then-wife and her inclusion in some advertisements, including for the Bijan Cologne campaign, as well as in Space Jam (where she is played by Theresa Randle), has important repercussions for the representation of the African American family. Repeatedly, references to the idyllic nuclear family are reiterated in association with Jordan suggesting an ideal for American society as a whole, including the dedication in 1996 of the 'Jordan Institute for Families' at the University of North Carolina. Jordan's home space is also depicted idyllically in Space Jam, firstly through the awed expressions of Jordan's assistant 
Stan Podolak (Wayne Knight) when he first encounters the player's impressive house after dropping him home following a baseball game. Jordan's own nuclear family of father, mother (Juanita (Theresa Randle), and three children (Jeffery (Manner Washington), Marcus (Eric Gordon) and Jasmine (Penny Bae Bridges)) are also prominently featured in the film. Significantly, though played by actors, his wife (at the time the film was made) and children's names are kept for the film adding to the associations with Jordan's actual life outside the diegesis.

Jordan's wife plays the supportive role of the housewife in the film, only depicted in association with their children in the domestic space or in the crowd at Jordan's final baseball game. While the uncomplicated and idyllic depiction of Jordan's nuclear family in Space Jam may have some basis in the player's actual life, as noted by McDonald and Andrews,

the simplistic celebration of the nuclear family continues to be used by members of the New Right to demonize poor single women with children who are simultaneously blamed both for their own poverty and the perceived collapse of national morality. Rather than look critically at the engendered division of labor and institutional racism, the intense focus on the alleged naturalness of the nuclear family with the stay at home mother and breadwinner father renders invisible a series of political and economic issues that have a huge impact on the poor (2001: 30-31).

Space Jam provides a seductive depiction of African American masculinity and family life. However, this utopian portrayal relies on conventional constructions of race, gender, and the family that disguises the reality for many Black families and may, in line with the American Dream itself, contribute to the perception of the marginalised and underprivileged as deviant.

Conclusion: Zidane, un portrait du 21e siècle (Zidane: A 21st Century Portrait)

In the United States, sport stars have provided crucial affirmation of the American Dream ideology despite the considerable evidence that questions the validity and appropriateness of this belief for understandings of American society today. The focus on the individualistic achievement, good character and most importantly humble origins of sport stars in film and other popular representations seems to offer dramatic evidence of the openness of opportunity to those with appropriate 'values', including hard work and perseverance, within American society. Sports stars, such as Babe Ruth in the past and Michael Jordan more recently, have been crucial to the persistence of this individualist ethic, a central aspect of contemporary capitalist culture internationally. To conclude, this essay will consider one of the most sophisticated and revealing recent productions to reflect on celebrity and its role in contemporary culture, the 2006 film Zidane, un portrait du 21e siècle (Zidane: A 21st Century Portrait). Though neither an American film, nor concerned with an American celebrity, the film is nonetheless a relevant critique of sport celebrity in that country, and indeed, internationally.

Zidane was made using 17 cameras, including some of the most powerful zoom lenses in the world acquired from the US military, positioned throughout the Santiago Bernabeu Stadium, home of the Spanish association football club Real Madrid. All of these cameras were focused on capturing the iconic French player and threetime FIFA World Player of the Year Zinedine Zidane while playing for his club Real Madrid against Villareal on April 23 $3^{\text {rd }}$ 2005. Zidane moves between television footage, particularly when the player is in possession of the ball, and $35 \mathrm{~mm}$ footage of Zidane moving around the pitch when off the ball. By this approach, the television footage provides a context for the images of Zidane and follows the ball in play while the $35 \mathrm{~mm}$ footage focuses on the man himself (fig. 3) and his expressions, movements and, through titles, his thoughts.

In this way, the film provides a neat commentary on the predominant focus of television and film respectively with regard to the representation of sport. As Dauncey and Morrey have noted, drawing on the work of Charles Tesson, it is the ball that legitimises editing in televised football, with its movement motivating 'changes in angle and focal length as well as camera movement' (Dauncey and Morrey, 2008: 310). Sport films have often failed to capture sporting events convincingly, lacking the dynamism and immediacy of television. As summarised by American film critic Andrew Sarris, 'Sports are now. Movies are then. Sports are news. Movies are fables' (Sarris, 1980: 50). Therefore, sport films have tended to focus beyond the sporting world, often considering the challenges athletes face in combining their life outside the ring or off the pitch with their athletic careers. Zidane in its $35 \mathrm{~mm}$ images of the player is less concerned with the 
game itself and more with examining the player as a person, though significantly, this examination reveals limited results.

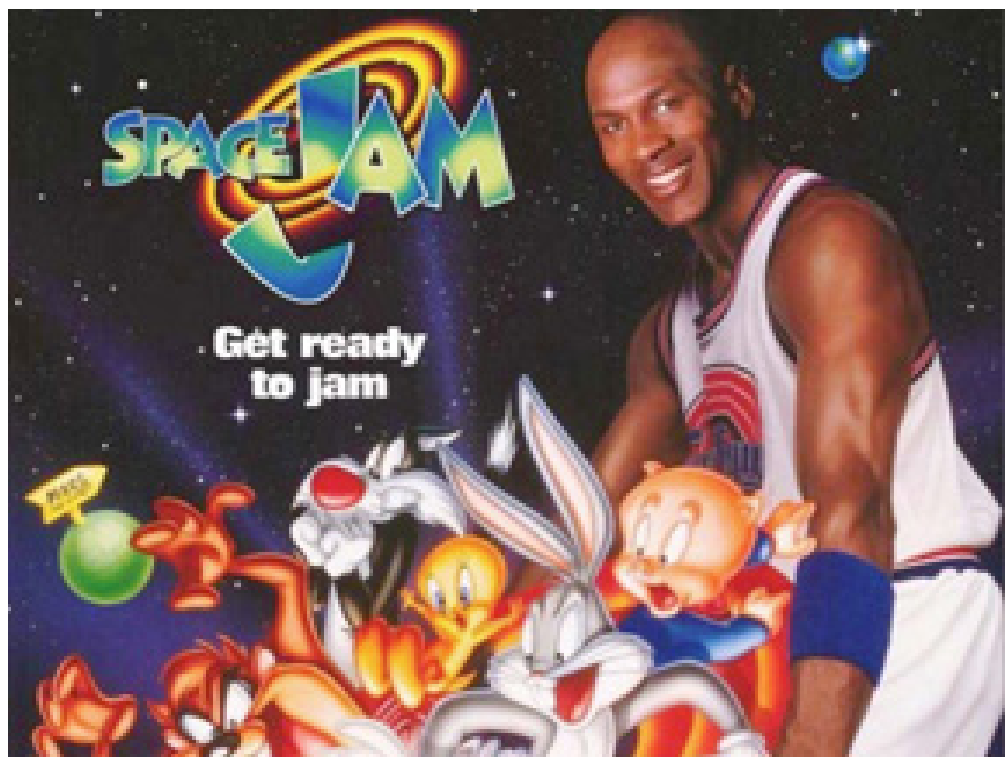

Figure 2: Figure 2: Publicity poster for Space Jam (Warner Bros, 1996) with Michael Jordan.

Indeed, despite the extraordinary lengths the filmmakers go to, to capture and reveal Zidane - as the opening title indicates 'Face to Face as close as you can for as long as it lasts, for as long as it takes' -, including communicating the player's thoughts through titles, the film ultimately suggests the impossibility of really getting to know the star athlete through film or in understanding him/her. If, as Dauncey and Morrey observe,

this portrait looks closer than ever before at Zidane, it ultimately has no secret, no truth to reveal about the player ... [the film's directors] [Douglas] Gordon and [Philippe] Parreno have stated that they chose Zidane as the focus for their film precisely for his indecipherable quality, and that, despite the sense of proximity to the player during the film, the spectator is left essentially knowing nothing more about him (Dauncey and Morrey, 2008: 309).

In its attempt, and ultimate failure, to reveal something private and distinct about Zidane, the film provides a commentary more generally on the notion of stardom itself and the manner through which stars 'bespeak our society's investment in the private as real' and the belief that 'what the star really is can be located in some inner, private, essential core' (Dyer, 1986: 12). For Dyer,

This is how the star phenomenon reproduces the overriding ideology of the person in contemporary society. But the star phenomenon cannot help being also about the person in public. If the magic, with many stars, is that they seem to be their private selves in public, still they can also be about the business of being in public, the way in which the public self is endlessly produced and remade in presentation (1986: 12).

This is precisely what Zidane provides us with, through its varied and changing perspectives on the player, from both television coverage and the $35 \mathrm{~mm}$ footage recorded by the filmmakers in the stadium. Through this process, the player is both produced and repeatedly remade, built from the various images to provide a seemingly complete and complex picture of the man, though one that ultimately gives limited insight into the person. This conclusion is symbolised in the opening of the film with an extreme zoom in on the television coverage of the match to such an extent that it is reduced to coloured pixels from which it is impossible to discern a coherent image (Dauncer and Morrey, 2008: 309).

Zidane also speaks to the instability of the star system itself, in its shaking and shifting perspective. As Dyer contends, 
the fact that we know that hype and the hard sell do characterise the media, that they are supreme instances of manipulation, insincerity, inauthenticity, mass public life, means that the whole star phenomenon is profoundly unstable. Stars cannot be made to work as affirmations of private or public life. In some cases, the sheer multiplicity of the images, the amount of hype, the different stories told become overwhelmingly contradictory (1986: 16).

Indeed in Zidane, the player himself provides a less than perfect exemplar for those following the game, and particularly children, striking an opposing player in the second half and getting sent off for the infringement.

As noted in previous work, the sport film has been characterised by the recurring failure to provide either a social or historical context for the events depicted (Crosson, 2013). Indeed, a central trope of this genre is the prioritising of the individual, and individual action, as the means to progress and success. Zidane ultimately questions this trajectory. While appearing to be concerned principally with the actions of one player, all of the meaningful action in which Zidane is involved is actually relayed via television images that foreground the team as a whole rather than the individual shots of the player depicted by $35 \mathrm{~mm}$ footage. Furthermore, the film not only provides context for Zidane's actions on the pitch, it also references the larger context for the game itself in terms of other events happening on the same day.

This is evident at half time, when the film turns to contemporaneous images from around the world, including events of much more serious import, from the destruction of homes in Serbia-Montenegro during the worst floods in forty years to the aftermath of a car bomb in Iraq in which 9 people are killed. Sport is not divorced from such events, however, as evident in the Real Madrid shirt (with Zidane's name on the back) worn by one of those filmed in the aftermath of this bomb attack. However, such images ultimately question the efficacy of sport as a means to either understand or overcome such larger social traumas, as sometimes suggested in the mainstream sport fiction film (Crosson, 2013).

These half-time images are intercut with Zidane's thoughts: 'Who could have imagined that in the future an ordinary day like this might be forgotten or remembered as anything more or less significant than a walk in the park'. In these comments, Zidane connects the future with the past and historicises the events that we are witnessing, whether trivial or socially important, adding an element often absent in the popular sport films. By moving from the individual to the social and raising questions about history, Zidane ultimately highlights the contemporary obsession with individualism and celebrity that capitalist consumerist culture promotes, while also questioning its efficacy in understanding our society or the world today.

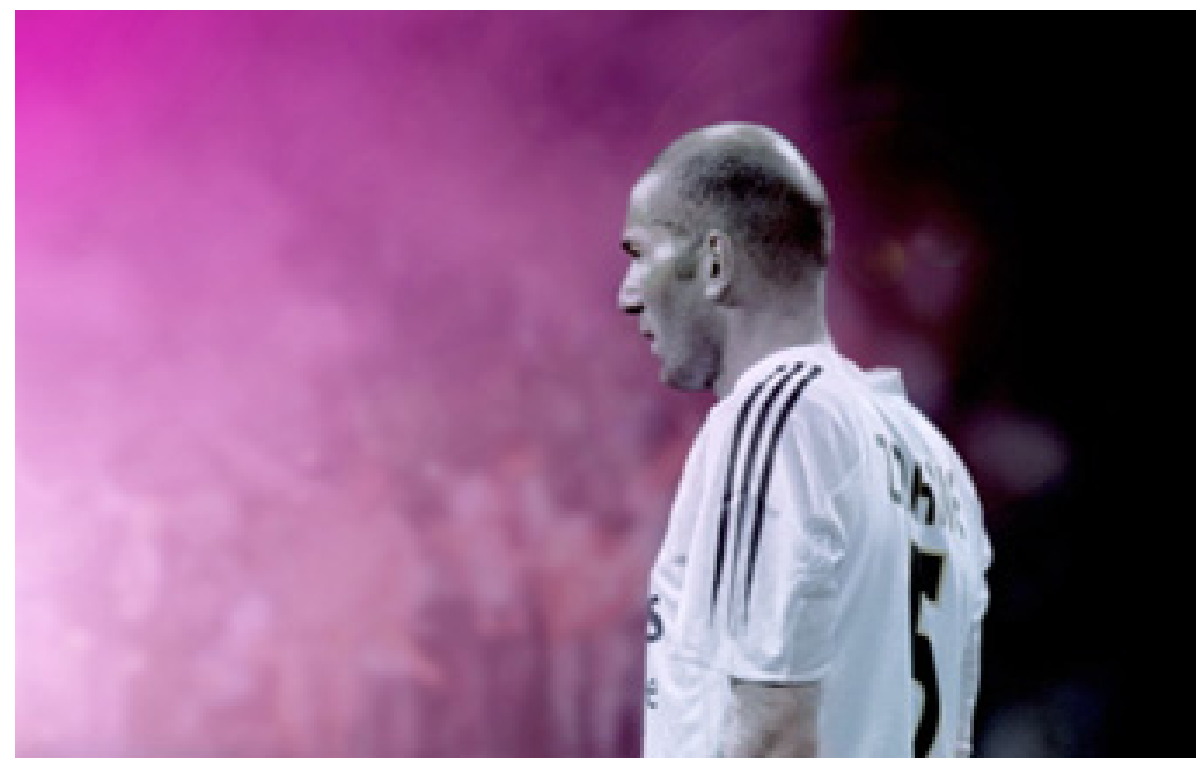

Figure 3: Figure 3: Film still, Zidane, un portrait du 21 siècle (Universal Studios, 2006). 


\section{Notes}

1. These figures are available from boxofficemojo at http://boxofficemojo.com/movies/?id=spacejam.htm

2. As the founder of the Olympic Games Baron Pierre de Coubertin remarked 'The most important thing in the Olympic Games is not winning but taking part; the essential thing in life is not conquering but fighting well' (quoted in Davies, 2006: 321).

3. For further on this see Smith, 2009: 98-101, and Gates, 2004.

\section{References}

Anonymous, 'Nike workers 'kicked, slapped and verbally abused' at factories making Converse', The Daily Mail, 13 July 2011,

http://www.dailymail.co.uk/news/article-2014325/Nike-workers-kicked-slapped-verbally-abused-factoriesmaking-Converse-line-Indonesia.html\#ixzz35eYCkHA3

Andrews, David L. \& Jackson, Steven J. (eds.) (2001) Sport Stars: the cultural politics of sporting celebrity London: Routledge.

Altman, Rick (1999) Film/Genre London: BFI Publishing.

Crosson, Seán (2013) Sport and Film London: Routledge.

Dauncey, Hugh and Morrey, Douglas (2008) 'Quiet contradictions of celebrity: Zinedine Zidane, image, sound, silence and fury', International Journal of Cultural Studies, 11(3): 301-320.

Davies, Richard O. (2006) Sports in American Life: A History Malden, MA; Oxford: Wiley-Blackwell.

Dyer, Richard (1986) Heavenly Bodies: Film Stars and Society London: British Film Institute.

Edgington, K., Erskine, Thomas, and Welsh, James M. (2010) Encyclopedia of Sports Films Lanham, MD: Scarecrow Press.

Fuller, Linda K. (1991) '"Triumph of the underdog" in baseball films'. In Loukides, Paul \& Fuller, Linda K. (eds.) Beyond the Stars, Vol. 2: Plot conventions in American popular film Bowling Green, OH: Popular Press. Pp. 53-60.

Gates, Henry Louis (2004) 'Breaking the silence', New York Times, 1 August, viewed 15 June 2014,

Giulianotti, Richard (1999) Football: a sociology of the global game, Cambridge: Polity.

Hirschhorn, Clive (1981) The Hollywood Musical New York: Crown Publishers.

Klapp, Orrin E. (1969) Collective Search for Identity, New York: Holt, Rinehart and Winston Inc., 1969.

LaFeber, Walter (1999) Michael Jordan and the New Global Capitalism New York and London: W. W. Norton \& Company.

Lane, Megan (2008) 'Which Wuthering Heights character are you?', BBC News Magazine, 10 July 2008, viewed 22 August 2011,

Manchel, Frank. (1980) Great Sports Movies, New York: Franklin Watts.

Monaco, James (1978) Celebrity. New York: Dell Publishing Co., Inc.

Nixon II, Howard L. (1984) Sport and the American Dream. Champaign, IL: Leisure Press/Human Kinetics.

Noverr, D. A., \& Ziewacz, L. E. (1983). The games they played: Sports in American history, 1865-1980. Chicago: Nelson-Hall. 
Rader, B. G. (1990). American sports: From the age of folk games to the age of televised sports (2nd ed.). Englewood Cliffs, NJ: Prentice Hall.

Robson, Tom (2010) 'Field of American dreams: individualist ideology in the U.S. baseball movie', Jump Cut: A Review of Contemporary Media 52, viewed 1 November 2011.

Sarris, Andrew (1980) 'Why sports Movies don't work' Film Comment, 16 (6): 49-53.

Smith, Earl. (2009) Race, Sport and the American Dream. Durham, NC: Carolina Academic Press. 2nd edition. (1st edition, 2007.)

Trimble, Patrick (March 1996) 'Babe Ruth: The Media Construction of a 1920's Sport Personality' Colby Quarterly, 32 (1): 45-57.

Tudor, Deborah V. (1997) Hollywood's Vision of Team Sports: Heroes, Race, and Gender New York and London: Garland Publishing.

Umphlett, Wiley Lee (1984) The movies go to college: Hollywood and the world of the college-life film Rutherford: Fairleigh Dickinson University Press.

Whannel, Garry (1998), 'Individual Stars and Collective Identities in Media Sport'. In Roche, Maurice (ed.) Sport, Popular Culture and Identity, Aachen: Meyer \& Meyer Verlag. pp. 23-36.

\section{Author Information}

Seán CROSSON is programme director of the MA in Film Studies: Theory and Practice with the Huston School of Film \& Digital Media in NUI Galway. Dr. Crosson's research interests include Irish film, film and sport, and the relationship between music and poetry. He is the author of a study of the sports film genre, Sport and Film (Routledge, 2013). 